\title{
Edward Tylor e a extraordinária evolução religiosa da humanidade
}

\author{
Frederico Delgado Rosa
}

resumo Contrariamente a certas ideias feitas sobre a Antropologia vitoriana, o presente artigo procura demonstrar que Edward Tylor não procurou acentuar as diferenças entre nós e os selvagens, mas, pelo contrário, demonstrar a comunhão profunda entre as religióes de uns e outros. A humanidade dita civilizada não vivia num estádio de ciência, mas num mundo impregnado de animismo, de caóticas contradiçóes entre as crenças adaptadas pela erudição teológica, as meras sobrevivências sem sentido e os ressurgimentos de fenómenos espiritistas que se julgavam há muito desaparecidos. Mais do que um exemplo de evolucionismo dogmático, sua obra Primitive Culture é uma tentativa de responder à questão das repetiçóes de conteúdo e das limitaçôes flagrantes ou básicas do pensamento humano, em todos os tempos e lugares, em matéria de imaginação de entidades sobrenaturais. Questão demasiado ambiciosa ou demasiado ingénua, foi abandonada pela Antropologia do século XX e continua sem outra resposta.

palavras-chave Animismo. Edward Tylor. Evolucionismo. Religiáo.

Em qualquer manual ou coletânea de textos do passado da Antropologia, Edward B. Tylor (1832-1917) é presença obrigatória. Acontece que sua obra-prima, Primitive Culture, tem sido objeto de leituras parcelares e apressadas ou simplesmente de falta de leitura. Regra geral, os estudantes universitários do século XXI, para não falar dos próprios docentes, conhe- cem apenas uns quantos parágrafos do primeiro ou do segundo capítulo, os preferidos das compilaçôes e justamente aqueles que mais induzem em erro quando separados do resto (Cf. Erickson \& Murphy, 2008; McGee \& Warms, 2008). Porquê perder tempo com dois pesados volumes de 1871, num total de cerca de mil páginas de teoria obsoleta e de etnografia pré-moderna em segunda mão? Para tentar responder a essa pergunta é necessário antes de mais devolver a Tylor o seu próprio pensamento, passando por cima de algumas ideias feitas. O presente artigo pretende contribuir para isso, na convicção de que uma surpresa espera aqueles que se derem ao trabalho de ler Primitive Culture na íntegra (Cf. Stringer, 1999, p. 542). Para não ficarmos encerrados em leituras de antiquário que muitas vezes só interessam aos especialistas, trata-se igualmente de explorar novas mensagens nos livros antigos, como vem advogando a canadiana Regna Darnell (2001), em alternativa ao historicismo exacerbado de George W. Stocking Jr.

Uma das ideias correntes acerca dos antropólogos evolucionistas vitorianos consiste em dizer que eles estabeleciam de forma rígida as etapas de evolução social ou cultural da humanidade e que, para caraterizar cada etapa, selecionavam determinados povos da atualidade, dos mais "primitivos" aos mais "civilizados". Criou-se entấo o termo pejorativo de evolucionismo unilinear, para se referir a essa 
doutrina segundo a qual havia uma linha de progresso ao longo da qual se distribuíam as várias culturas. É verdade que alguns autores foram evolucionistas unilineares, mas nem todos o foram e, sobretudo, "o mais sábio e mais equilibrado", aquele que exerceu maior influência no seu tempo, Edward Tylor, seguramente não foi um evolucionista unilinear (Kroeber, [1950] 1993, p. 220). Ele era muito cauteloso quanto a estabelecer uma escala de evolução e apenas sugeria essa ideia grosso modo, como um pressuposto genérico de que a humanidade começara sua caminhada numa condição da qual estavam mais próximos, em termos relativos, os povos sem escrita ainda existentes. Tylor considerava no entanto uma ilusão acreditar que o progresso das sociedades era coerente nos vários critérios, tecnológico, político, religioso etc. Não esqueçamos que no século XIX, sobretudo nos anos 1860, e mesmo antes, foram precisas muitas discussões, nomeadamente em Inglaterra, para demonstrar que náo se tratava de descendentes de Adão e de Noé, decaídos e esquecidos de um estado religioso e moral mais elevado, cuja origem remontava a uma criação e revelação divinas, como pretendia a ortodoxia bíblica. Constituiu-se então o conceito geral de selvagens contemporâneos, para exprimir a ideia - que Tylor sempre apresentava como uma hipótese - de que os povos sem escrita, ou tecnológica e politicamente frustres, representavam em termos globais um nível cultural mais próximo de uma condição primitiva.

É muito difícil, no presente artigo, evitar o emprego um tanto cansativo dos termos selvagem e civilizado, mas o importante mesmo é salientar que a ideia de selvajaria tinha sobretudo um valor relativo. Tylor não pretendia dizer que os chamados selvagens eram fiéis representantes das origens e menos ainda que eles não tinham cultura ou civilização, palavras sinónimas na sua obra. Assim, o que ele verdadeiramente queria dizer é que havia uma civilização selvagem - ou seja, a cultura primitiva do título da obra - e uma civilização civilizada (passe o pleonasmo), conservando esse último adjetivo um duplo sentido, pois tinha uma conotação suplementar de sofisticação cultural associada basicamente à escrita. De uma forma ou de outra, a ideia geral de que o progresso tinha marcado a história da humanidade era tudo quanto bastava a Tylor para cumprir seu verdadeiro objetivo de comparação entre o mundo dito selvagem e o mundo dito civilizado. E que objetivo era esse? Será que a dicotomia foi criada para acentuar as diferenças entre nós e os outros? Nós, os civilizados, e os outros, os selvagens? Não. O que aconteceu foi exatamente o contrário.

O grande objetivo da Antropologia de Tylor era demonstrar que o homem europeu, e mais genericamente o homem dito civilizado, estava profundamente impregnado de selvajaria. Em analogia com Charles Darwin, que já havia demonstrado à burguesia e aristocracia vitorianas que dentro delas tinham um primata, Edward Tylor queria pôr em evidência a costela culturalmente selvagem dos seus pares. A própria expressão tinha uma componente provocatória, não apenas em relação ao homem civilizado moderno, mas também em relação aos domínios sacrossantos da Antiguidade Clássica, cujos peritos não queriam nem ouvir falar em comparaçōes dos ilustres Gregos e Romanos com os aborígenes australianos ou outros. O mesmo acontecia, aliás, com os especialistas da Índia e de outras áreas de civilização urbana antiquérrima. Uma frase de Andrew Lang, discípulo de Tylor, resume bem o espírito iconoclasta da Antropologia vitoriana: "O homem nunca pode ter a certeza de ter expulsado o selvagem dos seus templos e do seu coração" (Lang, 1887, vol. I, p. 338). Encontramos uma imagem similar no célebre The Golden bough de James Frazer (1890), quando 
este afirmava que caminhamos hoje sobre uma fina crosta por baixo da qual se revolve uma matéria selvagem sempre pronta a entrar em erupção. Toda essa plêiade estava bem ciente de que, empiricamente falando, a ciência não existia como estádio evolutivo. A realidade dos homens era contraditória e, em certo sentido, caótica. É portanto uma ideia preconcebida acreditar que a Antropologia evolucionista britânica acentuava as fronteiras entre o mundo selvagem e o mundo civilizado.

$\mathrm{E}$ foi nesse contexto um tanto radical que a caraterização da religião dos selvagens contemporâneos ganhou protagonismo, por razóes óbvias. Tylor constatava que todos os tipos de crenças das sociedades civilizadas, do presente ou do passado, tinham os seus equivalentes, de uma forma ou de outra, em populaçóes cujo grau de cultura era julgado mais arcaico, mais primitivo. Era como se as grandes naçóes não tivessem inventado nada ou quase nada em matéria de artigos de fé, mas apenas herdado e adaptado uma série de crenças e rituais dos seus antepassados mais longínquos. Por exemplo, a metempsicose, ou seja, a transmigração ou reencarnação das almas, era uma crença que se encontrava tanto em povos selvagens $\mathrm{da}$ África Ocidental, da Austrália ou das Américas, como em populaçóes civilizadas, hinduístas e budistas, dos meios urbanos da Ásia meriodinal. Tylor não hesitava em reconhecer os fundamentos pré-históricos desse artigo de fé, mas considerava naturalmente que Hinduísmo e Budismo tinham introduzido nele certas "subtilezas metafísicas" segundo o espírito ético de contextos refinados ([1871] 1903, vol. I, p. 9-12). O mesmo resultado se repetia com praticamente todas as concepçóes das grandes religiôes politeístas da Antiguidade Clássica e Oriental e até, em certo sentido, das religióes monoteístas, como veremos mais adiante. $\mathrm{O}$ autor conseguia na verdade encontrar paralelos para tudo, quer no sentido ascendente, quer no descendente, mas conservando-se em todos os casos uma essência comum de origem pré-histórica.

Primitive Culture é um monumento à semelhança profunda e essencial das concepções religiosas da humanidade inteira, e cada capítulo da obra uma liçáo de comparatismo universal. Tratava-se de uma tipologia dinâmica, criando uma vasta série de categorias religiosas de muito longa duraçáo. Estamos perante um dos princípios fundamentais da Antropologia de Tylor, isto é, a ideia de desenvolvimento dos diferentes artigos de fé primitivos. Não havia uma substituição de umas crenças por outras, de acordo com uma sequência estabelecida de etapas de evolução religiosa, mas sim uma permanência de ideias pré-históricas, sujeitas a progressivas e variadíssimas adaptaçóes, de ordem moral, filosófica, estética, etc. Tylor tinha noção de que esses percursos respondiam às idiossincrasias culturais dos diferentes povos, só que não era esse o objeto da sua pesquisa. Primitive Culture é antes uma enciclopédia das categorias religiosas da humanidade, sempre identificáveis em todos os níveis de civilização e, neste sentido, pode-se extrair da obra a ideia de um património ideológico de origem pré-histórica.

Convém precisar que os vários tipos de crenças não tinham uma distribuição necessária, nem no tempo, nem no espaço. Ainda que a recorrência de algumas crenças fosse especialmente acentuada, havia outras que estavam longe de ser universais. Por exemplo, a categoria específica de demónios noturnos que copulavam com homens ou mulheres era identificada por Tylor nas Antilhas, na Nova Zelândia, nas ilhas Samoa, na Lapónia e na Índia, mas não em toda a parte. Curiosamente, a leitura de Santo Agostinho permitia constatar que na Europa do séc. IV e V d.C. existiam noçốes desse género entre as camadas populares. Teólogos mais tardios, da Baixa Idade 
Média, foram responsáveis, segundo Tylor, por incorporar tal crença no próprio seio da Igreja, culminando no célebre manual dos inquisidores, Malleus Maleficarum. Era a oficialização imprevista dos famigerados íncubos e súcubos, cujos parceiros sexuais presumidos eram perseguidos pelo Santo Ofício. (Tylor [1871] 1903, vol. II, p. 189-191).

Mas então, se havia essa variabilidade, com diferentes ideias em diferentes populaçóes, como era possível agrupar todas elas, canalizando-as no tempo para um mesmo fundo pré-histórico universal? Donde vinha a possibilidade de criar o conceito de religiâo primitiva aonde toda a humanidade tinha ido beber? Essa possibilidade devia ter a ver forçosamente com a existência de certas caraterísticas essenciais que lhes eram comuns. Em Primitive Culture, Tylor identificou-as, ou acreditou identificá-las. $\mathrm{O}$ cimento, aquilo que lhe permitiu falar em cultura primitiva, e mais especificamente em religião primitiva, foi aquilo a que ele chamou de animismo:

Proponho aqui, através do termo animismo, investigar a enraizada doutrina dos seres espirituais, que dá corpo à própria essência da filosofia espiritualista, em oposição à materialista. (...) $\mathrm{O}$ animismo carateriza tribos situadas muito na base da escala da humanidade, e daí ascende, profundamente modificado na sua transmissão, mas conservando do princípio ao fim uma continuidade ininterrupta, até ao seio da cultura moderna mais elevada. (...) E embora à primeira vista possa parecer uma magra definição mínima de religião, revelar-se-á suficiente na prática, pois onde estão as raízes, encontram-se os ramos. (...) Ao empregarmos o termo animismo para designar a doutrina dos espíritos em geral, estamos a afirmar que as ideias relativas às almas, aos demónios, às divindades e às outras classes de seres espirituais, são todas elas concepçóes com uma natureza análoga (Tylor [1871] 1903, vol. I, p. 425426; o itálico é nosso).

O termo animismo, formado a partir do latim anima, expressava a ideia de que todas as categorias religiosas, todas as crenças em seres espirituais, com suas muitíssimas variedades, seriam derivaçôes psicológicas de uma categoria verdadeiramente omnipresente: a noção de alma. Dito por outras palavras, Tylor estava persuadido que, entre todos, esse artigo de fé tinha constituído na pré-história uma espécie de protótipo a partir do qual tinham sido forjadas, também logo na pré-história, todas as outras crenças. Já sabemos que as categorias secundárias não eram forçosamente universais, pois sua presença variava consoante os povos, mas tinham apesar de tudo uma essência comum, uma essência animista, em relação com a noçáo de alma. Estava encontrada a ideia elementar, a categoria aglutinadora do património ideológico selvagem. Tylor caraterizou-a da seguinte forma, a partir de uma comparação etnográfica vastíssima:

É uma imagem humana, imaterial, uma espécie de vapor, uma nuvem, uma sombra. É a causa da vida e do pensamento no indivíduo que ela anima. É dona da consciência e da vontade do seu possuidor corporal, presente ou passado. Pode deixar o corpo longe de si e viajar rapidamente. É geralmente impalpável e invisível, mas também suscetível de manifestar alguma propriedade física. Aparece aos homens durante o sono, como um fantasma separado do corpo mas conservando a sua aparência. Após a morte do corpo, ela continua a existir e a aparecer e tem a faculdade de entrar, dominar e agir no corpo de outros homens, animais e mesmo em objetos inanimados. Sem dúvida, estas caraterísticas exatas da alma não são todas elas universais, mas são suficientemente generalizadas para apreendermos a ideia-tipo, com divergências 
mais ou menos acentuadas de povo para povo. É que estas ideias, que encontramos em toda a parte, não são produtos meramente arbitrários e convencionais do espírito humano. Longe disso. São teorias que derivam forçosamente do testemunho indubitável dos sentidos, tal como o interpreta uma filosofia primitiva realmente consequente e racional. (Tylor, [1871] 1903, vol. I, p. 429).

É bem sabido que, segundo Tylor, a humanidade primitiva teria meditado sobre as causas de certos fenómenos biológicos, tais como o sono, o sonho, a doença, a morte, e chegado à conclusão muito natural de que cada indivíduo possuía uma alma separável do corpo, cujas deslocaçóes explicavam aqueles fenómenos. Quando a alma deixava o corpo definitivamente, este morria. Mas se Tylor foi muito criticado no século XX por falar em "filósofos selvagens", na realidade ele não utilizava esse termo para caraterizar a inteligência ou a curiosidade intelectual acima da média de figuras singulares do passado pré-histórico da humanidade. Tratava-se antes de mecanismos psicológicos elementares e universais, de mera associação de ideias. O "filósofo selvagem" era a humanidade inteira, porque a psicologia humana pendia naturalmente para o animismo. Tylor introduzia o conceito de religião natural para exprimir esse caráter inevitável e universal ([1871] 1876, vol. II, p. 142). Com efeito, as demais categorias religiosas eram derivaçóes psicológicas do mesmo género. Havia em particular duas concepções básicas fundamentais que resultavam diretamente da ideia de alma e que permitiam compreender o surgimento de todas as categorias, incluindo os diferentes tipos de deuses. Por um lado, era a animação ou personificação da natureza, ou seja, a atribuição de uma alma a animais, plantas, montanhas e outros objetos exteriores. Por outro lado, era a formação espontânea da noção de espírito a partir da noção de alma separada do corpo. Em síntese, Deus não criara o homem à sua imagem, mas sim o contrário (Cf. Stocking Jr., 1987, p. 195).

Importa frisar que Tylor náo via o conceito de alma e as derivaçóes do mesmo como etapas da evolução religiosa da humanidade, nem nunca utilizou a etnografia contemporânea nesse sentido. As crenças elementares não eram substituídas pelas derivações mais complexas seguindo uma ordem sequencial. Pelo contrário, todas as ramificações do animismo eram basicamente simultâneas e detectáveis entre as populaçóes primitivas ainda existentes. Tratava-se pois de uma acumulação original das diferentes categorias, forjadas globalmente numa mesma condição pré-histórica, desde a noção de alma até diferentes tipos de divindades, inclusive deuses supremos selvagens comparáveis aos das religióes monoteístas, passando por algumas dezenas de categorias respeitantes à natureza, às funçóes e aos atributos de seres animados ou espirituais, do totem ao vampiro, do fétiche ao espírito do vulcáo, do anjo da guarda ao deus do mar. $\mathrm{O}$ índice geral de Primitive Culture representa, só por si, uma empresa classificatória. O quadro era completado com uma referência à magia. Não se tratava, note-se bem, de um fenómeno animista - ou religioso - pois náo implicava em si mesma seres espirituais. Derivava todavia de um processo elementar, para não dizer inelutável, de associação de ideias, fazendo parte integrante do património ideológico pré-histórico, ao mesmo título que as manifestações animistas.

Infelizmente, essa especificidade do evolucionismo tyloriano tem escapado a muitos leitores da sua obra. A verdade é que não se deve equiparar Tylor a um John Lubbock, por exemplo, que propunha no seu Origin of Civilization, de 1870, uma sequência propriamente unilinear de etapas religiosas sucedendo-se 
umas às outras. Eis alguns exemplos da falta de compreensão do alcance revolucionário do conceito de animismo na historiografia do século XX. "(...) depois dos começos da religiáo selvagem, absolutamente rudes ou simples, a humanidade percorria uma série de fases que tinham uma validade universal e que conduziam à religiáo monoteísta. Porque mais perfeita, esta era colocada no fim, numa evolução natural' (Bianchi, 1965, p. 62). Após uma breve exposição da sequência proposta por Lubbock, Ugo Bianchi consegue transformar as ideias de Tylor numa teoria dos três estádios: "Para Tylor, a sequência seguinte era válida: o animismo (dando por vezes lugar a fenómenos secundários, tal como o 'fetichismo'), em seguida o politeísmo e, por fim, o monoteísmo. Só o ponto de partida variava consoante os autores, uma vez que era o mais obscuro" (Op. cit., p. 96). Na verdade, cada qual pode encontrar em Primitive Culture a sequência de evolução que quiser, atribuindo aos capítulos enciclopédicos um aspecto de etapas que só existem na imaginação ou no preconceito do leitor, e não no texto original. Por exemplo, Marcel d'Hertfelt, autor de um manual de história da Antropologia para estudantes universitários, descobre em Tylor a seguinte ordem evolutiva: crença na encarnação de espíritos, concepção de deuses da natureza, concepção de deuses da atividade humana, e concepção de um deus único. (1992, p. 58). Ora, em Primitive Culture as divindades do politeísmo antropomórfico integravam uma categoria animista detectada em populaçóes selvagens:

Os grandes deuses do politeísmo, numerosos e elaboradamente definidos na teologia do mundo cultivado, não têm aí, contudo, seu primeiro aparecimento. Nas religióes dos povos mais rudes, seus tipos principais já estavam delineados, e a partir daí (...) se tornou tarefa do poeta e do sacerdote, do fazedor de lendas e do historia- dor, do teólogo e do filósofo, desenvolver e renovar, ou degradar e abolir, os poderosos deuses desses panteões ([1871] 1903, vol. II, p. 248).

Por reação ao degeneracionismo bíblico, Tylor se recusava sem dúvida a colocar um deus único na origem da religião, mas essa recusa era extensível a qualquer outra formação animista. Na pré-história teria havido grande variedade de religiôes, embora assentes em princípios comuns. Ele ia mais além e afirmava inclusive que os gérmens do monoteísmo e do próprio dualismo ético eram detectáveis entre alguns povos primitivos contemporâneos, o que não significava de forma alguma que toda a humanidade estivesse predestinada a acreditar num ser supremo. Mais tarde veio a acentuar a sua suspeição de que as ideias selvagens dessa ordem eram, em muitos casos, devidas a influências cristás, sobretudo nas suas componentes morais. $\mathrm{O}$ artigo "On the Limits of Savage Religion”, publicado em 1892, traduz essa inflexão, mas o título escolhido constitui só por si uma prova de que o campo de extensão da religiáo primitiva era praticamente ilimitado. Por um lado, o monoteísmo em estado puro era uma ficção. Historicamente, as religióes do Livro, e desde logo o Cristianismo, regorgitavam de concepçóes animistas para além da ideia de deus único, inclusive de outros seres espirituais com atributos divinos ou maravilhosos. Por outro lado, Tylor continuou identificando, mesmo nas ediçóes ulteriores de sua obra, exemplos selvagens que entravam no capítulo da categoria religiosa do deus supremo:

Se considerarmos que o critério do monoteísmo consiste simplesmente na ideia de uma divindade suprema criadora do universo e chefe da hierarquia espiritual, então sua aplicação à teologia selvagem e bárbara conduzirá a consequências surpreendentes. Povos da América do Norte e 
do Sul, da África, da Polinésia, são usualmente e legitimamente considerados politeístas, mas segundo aquela definiçáo o seu reconhecimento de um criador supremo (...) habilita-os ao mesmo tempo ao título de monoteístas ([1871] 1903, vol. II, p. 332).

Associando a Antropologia à filosofia materialista ou monista subjacente à ciência - por oposição justamente à filosofia espiritualista ou animista - Tylor encarava a religiáo como um processo de criação de imagens fantasiosas sobre a realidade, seguindo embora uma lógica natural e universal, porque simplesmente humana. Não era de estranhar que os antepassados pré-históricos tivessem inventado tudo o que havia para inventar nessa matéria. Nem podia ser de outra forma. E assim, a evolução religiosa da humanidade era um processo simultâneo de permanência e de transformaçáo do legado primitivo. Contudo, Tylor propunha, além do desenvolvimento, um segundo princípio interpretativo no estudo das relaçóes entre o homem selvagem e o homem civilizado. A par da adaptação progressiva das concepçóes animistas, justificando de certa forma a sua duração na História, as populaçóes ditas civilizadas também conservavam traços selvagens que não tinham verdadeiro sentido no novo ambiente. Tratava-se de ideias e usos cuja manutenção era apenas devida ao conservadorismo irrefletido, ao peso atávico da tradição. Eram as sobrevivências, as sobrevivências na civilização, ou survivals. Em Primitive Culture, Tylor dedicava dois capítulos a essa questão, tratada numa perspetiva teórica aprofundada. Sob o seu impulso, a teoria das sobrevivências se tornou um dos aspectos mais distintivos da escola antropológica inglesa. Nas suas palavras, uma sobrevivência era:

(...) a persistência de uma ideia cujo sentido se perdeu há muito tempo, mas que continua exis- tindo pela simples razão de que um dia existiu. (...) Podemos afirmar, de uma vez por todas, que os usos desprovidos de sentido devem ser sobrevivências, que eles tiveram uma intençáo prática ou pelo menos um caráter de cerimónia no momento e no lugar onde surgiram, mas que acabaram se tornando observâncias absurdas, porque foram transportados para um novo estado social onde sua significação desapareceu (Tylor, 1871, I, p. 64-85).

Como ilustração, o hábito europeu de saudar quando alguém espirrava era supostamente uma sobrevivência da época muito longínqua em que essa repentina saída de ar era associada à movimentação de entidades espirituais. Tal era a crença viva de numerosas populaçóes selvagens, o que permitia reintegrar a sobrevivência no seu contexto psicológico original. $\mathrm{O}$ conjunto das tradiçôes camponesas da Europa contemporânea, aquilo a que se chamava de folclore, fornecia exemplos abundantes de sobrevivências. Com efeito, os camponeses eram supostamente os descendentes das camadas mais estagnadas da população, tendo conservado uma herança pré-histórica considerável. $\mathrm{O}$ peso da tradição coletiva determinava a manutenção de usos cuja razáo de ser tinha-se obliterado ao longo dos séculos. Por exemplo, continuava-se repetindo lendas fabulosas - os chamados contos populares, que chegavam às crianças da cidade nas versóes recolhidas pelos irmãos Grimm e outros - sem que a existência real de suas personagens sobrenaturais constituísse forçosamente um artigo de fé nos meios rurais do século XIX. Dito isto, o aspecto incoerente, ou mesmo absurdo, dessas representaçóes permitia supor que se tratava de sobrevivências de uma era em que esses seres imaginários não eram apenas personagens de contos de fadas, mas verdadeiros agentes espirituais que povoavam o universo. Por outro lado, havia crenças que permaneciam bem vi- 
vas, com lobisomens e afins no horizonte psicológico dos camponeses, mas a contiguidade do folclore em relaçáo aos centros urbanos assegurava globalmente o seu estatuto de sobrevivência na civilização. De um modo geral, os fundamentos psicológicos que tinham estado na origem de muitas tradiçóes rurais da Europa já não eram considerados tão atuantes como entre os selvagens de além-mar.

Mas esse é apenas um lado da questão, aplicado ao mero conservadorismo de tradiçôes, outrora graves, que tinham adquirido ao longo dos séculos um aspecto simples, geralmente de merry-making ou distração coletiva nos campos. James Frazer, seguidor de Tylor, iria explorar enormemente esse filáo no seu célebre The Golden bough (1890). Mas que dizer de outro tipo de incongruências bem ativas, como era o caso dos métodos divinatórios e mediúnicos muito em voga nos salóes vitorianos? Vivendo numa era de apogeu do espiritismo, Tylor considerava-o uma flagrante contradição civilizacional e, por conseguinte, seria à primeira vista um excelente candidato ao título de sobrevivência. Na verdade, podia tratar-se de um revival mais do que um survival, o que reforça um aspecto bem ousado da teoria tyloriana, ou seja, a perceção de que a humanidade continuava, em todos os tempos, pendendo para o animismo, ou não fosse a sua religiāo natural, ancorada no próprio funcionamento da mente humana: "The thing that has been will be" ([1871] 1903, vol. I, p. 159). Tylor repetia com frequência que as noçôes de desenvolvimento e de sobrevivência davam conta da maior parte das manifestaçóes religiosas reunidas em Primitive Culture, mas havia de fato outros instrumentos concetuais que podiam ser tomados em linha de conta ocasionalmente, tais como sobrevivência parcial, degenerescência, desaparecimento e ressurgência ou revival. De qualquer forma, nem sempre ele precisava se a permanência histórica de uma crença ou de um rito de origem selvagem num meio civilizacional mais sofisticado era uma questão de sobrevivência ou de desenvolvimento.

Se a segunda hipótese sobressaía como uma tendência maior ao longo da obra, era por vezes de forma implícita. Tomemos como exemplo a ideia de dream-soul, segundo a qual as almas desencarnadas visitavam os vivos durante o sono. Tylor chegava ao ponto de dizer que ela era para os Gregos antigos exatamente o mesmo que era para o selvagem contemporâneo, o que poderia indicar uma falta de adaptação ao espírito da época clássica e, por conseguinte, uma forma de sobrevivência. Contudo, o veredito nem sempre é fácil. É possível admitir que, segundo seu pensamento, muitas noçóes primitivas persistiam quase inalteradas num novo estado social sem que no entanto fossem verdadeiras sobrevivências. Para empregar este conceito com toda a legitimidade, seria então preciso que de alguma forma se rompessem os laços de coerência ou articulação entre o contexto social e a crença - ou que simplesmente houvesse uma perda de fé. A partir do momento em que os Gregos no seu conjunto acreditavam firmemente na dream-soul, talvez fosse abusivo ver aí uma simples sobrevivência. O conceito de sobrevivência parcial, ainda que nem sempre explicitado, revela-se útil nesses casos.

Trata-se porém de uma das questóes mais delicadas e ao mesmo tempo aliciantes da obra de Tylor. De um modo geral, quando um elemento de origem pré-histórica estava perfeitamente integrado no processo de evolução religiosa e civilizacional de cada sociedade, de acordo com uma nova sensibilidade intelectual, ética, artística etc., o conceito de sobrevivência se revelava inapropriado. Infelizmente, as nuanças teóricas entre as noçôes de desenvolvimento e de sobrevivên- 
cia escaparam com frequência aos leitores de Tylor, seja do século XIX, seja do século XX. Assim se explica, entre outros, que um historiador táo reputado como John Burrow tenha dito, no seu estudo de 1966, Evolution and Society, que Tylor "declarava guerra às sobrevivências" quando retraçava as origens selvagens de certos elementos fundamentais do Cristianismo, como o batismo ou a consagração (conversão do páo e do vinho no corpo e sangue de Cristo durante a eucaristia) (1966, p. 256-257). Ora, Tylor não teria utilizado o conceito de sobrevivência nesses casos, mas sim o de desenvolvimento, alusivo a dezanove séculos de erudita teologia trabalhando tais mistérios - um trabalho de desenvolvimento iniciado aliás (melhor dizendo, continuado) por ninguém menos que Jesus Cristo. É curioso pensar que a própria posição de Tylor em matéria religiosa espelhava porventura essa delicada fronteira entre a rejeição e a conciliação (Cf. Stocking Jr., 1987, p. 188-197). Ele tampouco dizia que a definição cristã de alma imortal era uma simples sobrevivência do animismo selvagem, despojada de sentido e de razão de ser, mas não hesitava em ligá-las pelo conceito de desenvolvimento. A noçáo de alma, a mais importante categoria religiosa da humanidade, conservava sua essência ao longo de uma ascensão marcada por toda uma série de modificaçóes e adaptaçôes:

(...) apesar de tão profundas mudanças, é bem claro que a concepção da alma humana, no que toca de mais perto à sua natureza, não se modificou desde a filosofia do pensador selvagem até à do moderno professor de teologia. A alma, desde a origem, continuou sendo definida como uma entidade animadora, separável do corpo e sobrevivente, e concebida como o veículo da existência individual. A teoria da alma é uma das partes essenciais de um sistema de filosofia religiosa que une numa cadeia ininterrupta o selvagem adorador de fetiches ao cristão civilizado ([1871] 1876, vol. I, p. 584).

Notemos que as sobrevivências na civilização podiam também sofrer manuseamentos de todos os tipos, mas ao contrário das categorias religiosas que se tinham desenvolvido no sentido exato do termo, não estavam ligadas de forma orgânica e harmoniosa às novas condiçôes sociais e psicológicas. Sob uma roupagem refinada podia se esconder uma perfeita incongruidade cultural. Um bom exemplo eram as relíquias do Catolicismo, que Tylor considerava absurdos no respetivo tempo. $\mathrm{O}$ barroco da talha dourada não fazia mais do que camuflar a selvajaria dessa veneração com bastos paralelos na etnografia exótica. Não é de estranhar que a parafernália católica, com seu desfile secular de exorcismos e milagres, íncubos e súcubos, ossadas macabras e queima de bruxas, fosse bem rica de exemplos dessa ordem, muito apreciados por Tylor, ainda que os célebres revivals das seitas protestantes norte-americanas também pudessem fornecer dados excelentes.

O fato é que Tylor considerava indispensável em ambos os casos, tanto nos de sobrevivência, como nos de desenvolvimento, a caraterização antropológica da configuração primitiva de cada categoria religiosa. As versôes mais sofisticadas podiam bem conservar um significado ativo e ser objeto de uma crença atualizada, mas também deviam ser remergulhadas no ambiente pré-histórico. A antropologia da religião evolucionista, interessada em culturas a todos os níveis de civilização, seria doravante baseada na compreensão dos contornos psicológicos mais espontâneos e arcaicos do animismo selvagem, e nomeadamente do significado perfeitamente concreto e explícito do património religioso da cultura 
306 | Frederico Delgado Rosa

primitiva em geral. Em termos retrospetivos da História da Antropologia, uma das características mais criticadas ou criticáveis desse ponto de vista era a falta de atenção que Tylor dava às diferenças de sentido no interior da mesma categoria religiosa (ou daquilo que ele considerava ser uma mesma categoria religiosa). As crenças eram repartidas em tipos por simples analogia do seu conteúdo literal e interpretadas como consequência natural de uma lógica errada, mas compreensível. Desde o tempo de Evans-Pritchard, é um lugar comum afirmar que essa interpretação excessivamente racionalista dos dados etnográficos descurava as dimensóes simbólicas, emocionais e sociais dos fenómenos religiosos. Em lugar de tratar as religióes como sistemas, Tylor pulverizava suas componentes respetivas através dos dispersos capítulos da obra. À primeira vista, estamos perante uma drástica redução dos significados em cada contexto, como se o autor deixasse de fora tudo o que mais viria a interessar à Antropologia do século XX. No dizer de Alfred Kroeber, "o seu famoso método comparativo falhou, vemo-lo hoje, porque violava o contexto" (Kroeber, [1950] 1993, p. 220).

Convém todavia precisar que Tylor não estava procurando explicar - como náo estava procurando negar - as particularidades culturais e históricas desses fenómenos em seus respetivos lugares. Ele estava bem consciente de que as diversas concepçóes religiosas, tendo embora fundamentos psicológicos comuns, haviam sido forjadas em sociedade, o que explicava aliás as variaçóes flagrantes de cada tipo de crença, incluindo as características exatas da alma em diferentes contextos etnográficos. Para além disso, as próprias ideias de desenvolvimento e de sobrevivência eram inseparáveis de histórias concretas de transformação ou de conservadorismo social. Tylor se limitou a dar uma resposta, a sua respos- ta, a uma pergunta sobre a civilização no seu conjunto - em particular sobre a religiáo da humanidade - sem com isso negar as culturas ou civilizaçôes no plural. No fundo, o enigma de Primitive Culture tem a sua chave no título e nas palavras de abertura. O título resume o interesse do autor pela Cultura Primitiva da humanidade, com maiúscula e no singular, mas as palavras de abertura indubitavelmente definem a cultura na sua aceção plural, legando à Antropologia a mais citada definição do seu objeto de estudo: "Cultura ou civilização, tomada no seu sentido etnográfico alargado, é aquele todo complexo que inclui o conhecimento, a crença, a arte, a moral, a lei, o costume e quaisquer outras capacidades e hábitos adquiridos pelo homem enquanto membro da sociedade" ([1871] 1903, vol. I, p. 1). Em certo sentido, podemos dizer que Tylor não chegou a descontextualizar, simplesmente porque sua abordagem não era relativa aos contextos em si mesmos, pelo menos não de forma prioritária. A verdade é que a pergunta que ele formulou há 140 anos continua sem outra resposta, pois se Claude Lévi-Strauss revelou as similitudes do pensamento humano ao nível das formas, ninguém mais, em Antropologia, ousou demonstrá-las ao nível do conteúdo. Significará isso que elas simplesmente não existem? Porque é que a humanidade tem repetições e limitaçôes óbvias na sua imaginaçáo do sobrenatural? Eis o desafio que nos lança Primitive Culture.

Com Edward Tylor, a religiáo dos primitivos passou a ser um instrumento, bastante ousado no seu tempo, de explicação dos dogmas e da parafernália mitológica e ritual das religióes civilizadas, incluindo o Cristianismo. Foi um tempo em que a literatura etnográfica se tornou acima de tudo matéria-prima para pôr a nu os fundamentos selvagens de crenças supostamente superiores, como a Imaculada Conceição ou a própria ideia de 
homem-Deus, que esteve na base do sucesso estrondoso do The Golden bough, já na viragem para o século XX. Em paralelo, o ressurgimento urbano de fenómenos divinatórios, espiritistas e afins também ficava largamente coberto por essa Antropologia - e Tylor teria muito a dizer sobre o mundo de hoje, com suas versóes New Age da metempsicose, com suas revistas especializadas em anjos da guarda e tantos outros fenômenos "animistas" mais ou menos exteriores ou refratários às estruturas eclesiásticas do Cristianismo. Essa é uma das razões, entre outras, pelas quais Primitive Culture pode ser objeto de uma leitura apaixonante. É que Tylor teve uma visão sui generis da evoluçáo religiosa da humanidade. E por muito que o autor afirmasse seu caráter natural, ou ordinário, ao leitor não pode senão ficar a impressão de que ela foi realmente extraordinária.

\section{Edward Tylor and the Extraordinary Reli- gious Evolution of Humanity}

abstract Contrarily to certain current ideas on Victorian anthropology, this article tries to demonstrate that Edward Tylor did not intend to stress the differences between us and the savages; on the contrary, he demonstrated that there was deep communion between the religion of both. The so-called civilized humanity was not living in a status of science, but in a world entrenched in animism, chaotic contradictions between the beliefs adapted by theological erudition, mere senseless survivals, and the revival of spiritualist phenomena considered to have vanished long ago. More than an example of dogmatic evolutionism, Tylor's work Primitive Culture is an attempt at answering the question of recurring contents and flagrant or basic limitations in human thought, in every time and place, concerning the imagination of supernatural beings. This is either an all-too-ambitious or an all-to-naïve issue, which was abandoned by $20^{\text {th }}$ century anthropology and still awaits an answer.

keywords Animism. Edward Tylor. Evolutionism. Religion.

\section{Referências bibliográficas}

BIANCHI, Ugo. Storia dell'etnologia. Roma: Edizioni Abete, 1965.

BURROW, John W. Evolution and Society. A Study in Victorian Social Theory. Cambridge: Cambridge University Press, 1966.

DARNELL, Regna. Invisible Genealogies. A History of Americanist Anthropology. Lincoln, London: University of Nebraska Press, 2001.

D'HERTEFELT, Marcel. Anthropologie culturelle. Évolution - Histoire - Structure - Fonction. Liège: Presses Universitaires de Liège, 1992.

ERICKSON, Paul; MURPHY, Liam. Readings for a history of anthropological theory. Toronto: University of Toronto Press, 2008.

FRAZER, James George. The Golden Bough. A Study in Comparative Religion. London: MacMillan and Co., 1890.

KROEBER, Alfred L. A História e a atual orientação da Antropologia Cultural. In: A Natureza da Cultura. Lisboa: Edições 70, [1950] 1993.

LANG, Andrew. Myth, Ritual and Religion. London: Longman's, Green and Co., 1887. 2 v.

LUBBOCK, John, The Origin of civilization and the primitive condition of man, London: Longmans, Green, |1870|, 1882.

McGEE, R. Jon; WARMS, Richard L. Anthropological Theory. An Introductory History. Boston: McGraw Hill, 2008.

STRINGER, Martin D. Rethinking Animism: Thoughts from the Infancy of Our Discipline. In: Journal of the Royal Anthropological Institute, vol. 5, n. 4, p. 541-555, 1999.

STOCKING Jr., George W. Victorian Anthropology. New York: The Free Press, 1987.

TYLOR, Edward Burnett. Primitive Culture: Researches into the Development of Mythology, Philosophy, Religion, Art, and Custom. London: John Murray, 1871. La Civilisation primitive. Paris: C. Reinwald et. Cie., [1871] 1876. 2 v.

cadernos de campo, São Paulo, n. 19, p. 297-308, 2010 
308 | Frederico Delgado Rosa

Primitive Culture. Researches into the Development of Mythology, Philosphy, Religion, Language, Art, and Custom. London: John Murray, [1871] 1903.
On the Limits of Savage Religion. Journal of the Anthropological Institute of Great Britain and Ireland, London, vol. XXI, p. 283-299, 1892.

autor Frederico Delgado Rosa

Professor da Faculdade de Ciências Sociais e Humanas / Universidade Nova de Lisboa Doutor em Etnologia / Universidade de Paris X (Nanterre)

Recebida em 30/08/2010

Aceita para publicação em 30/08/2010

cadernos de campo, São Paulo, n. 19, p. 297-308, 2010 